\title{
Comparative study on microstructure and surface properties of keratin- and lignocellulosic-based activated carbons
}

\author{
Jiao-Jiao Kong ${ }^{\text {a }}$, Qin-Yan Yue ${ }^{\text {a, }}$, Pin Zhao ${ }^{\text {a }}$, Bao-Yu Gao ${ }^{\text {a }}$, Qian Li ${ }^{\text {a }}$, YanWang ${ }^{\text {a }}$, Huu \\ Hao Ngo ${ }^{\text {b }}$,Wen-Shan Guo ${ }^{\text {b }}$
}

a Shandong Provincial Key Laboratory of Water Pollution Control and Resource Reuse, School of Environmental Science and Engineering, Shandong University, Jinan 250100, China

b Centre for Technology inWater and Wastewater, School of Civil and Environmental Engineering, University of Technology, Broadway, Sydney, NSW 2007, Australia

* Corresponding author: e-mail address: qyyue58@aliyun.com (Q.-Y. Yue).

\begin{abstract}
The paper probed the preparation of activated carbon by potassium silicate $\left(\mathrm{K}_{2} \mathrm{SiO}_{3}\right)$ activation from keratin waste (cowhair waste, $\mathrm{CW}$ ) and lignocellulosic materials (Cyperus alternifolius, CA) and the comparisons of physicochemical properties of the resulting carbons. These impregnation conditions were as follows: one impregnated at room temperature for $12 \mathrm{~h}$ then dipped at high temperature for $30 \mathrm{~min}$; the other was only impregnated at room temperature for $12 \mathrm{~h}$, producing four activated carbons CWAC-1, CWAC-2, CAAC-1, and CAAC-2. The influence of activation time, $\mathrm{K}_{2} \mathrm{SiO}_{3} /$ precursor weight ratio, and the pre-process on properties of activated carbons was discussed. The CWAC-1 produced at $700{ }^{\circ} \mathrm{C}$ with the $\mathrm{K}_{2} \mathrm{SiO}_{3}$ /precursor weight ratio of 2:1 possessed the BrunauerEmmet-Teller (BET) surface area of $1965 \mathrm{~m}^{2} / \mathrm{g}$ and total pore volume of $1.345 \mathrm{~cm}^{3} / \mathrm{g}$, while CAAC-1 prepared at the same conditions attained the BET surface area of $1710 \mathrm{~m}^{2} / \mathrm{g}$ and total pore volume of $0.949 \mathrm{~cm}^{3} / \mathrm{g}$. The surface area and total pore volume of CAAC increased with the impregnation ratio. Moreover, CWAC-1, CWAC-2, CAAC-1, and CAAC-2 exhibited high portion of micropores, illustrating the role of $\mathrm{K}_{2} \mathrm{SiO}_{3}$. The analysis with a Fourier transform infrared spectrometer indicates that CWAC has more functional groups than CAAC, as well as CWAC-1 and CWAC-2 which possess similar functional groups.
\end{abstract}

Keywords: Activated carbon; Cowhair waste; Cyperus alternifolius; Potassium silicate 


\section{Introduction}

Activated carbon (AC) is well known as an effective adsorbent which is widely applied in the separation and purity process for wastewater and exhaust gas operation [1] and [2]. It is also used as a catalyst carrier, raw material of capacitor and solid-phase extractors from aqueous solutions [3]. ACs have many advantages, including large surface area, various oxygencontaining functional groups and stable chemical properties. It can be prepared by any carbon-rich substances, and its properties depend on the raw materials and methods of preparation.

Generally, in the process of AC preparation, the activation methods contain chemical, physical and the combination of both of them. For chemical method, the precursor is mixed with compounds such as phosphoric acid [4], potassium hydroxide [5], zinc chloride [6] and potassium carbonate [7] and [8], and then activated at various temperatures. The previous studies [9] have been reported that carbon activated by potassium hydroxide could possess high specific surface area and large number of micropores, but the apparatus would be corroded and the life of which lowers due to the strong basicity. Actually, silicone material is widely employed as a catalyst and fire retardant to prevent the flame of material in origin [10], and potassium silicate $\left(\mathrm{K}_{2} \mathrm{SiO}_{3}\right)$ has lower alkalescency than potassium hydroxide. In general, carbon prepared by potassium hydroxide consists of the pyrolysis of the precursor material and activation of the char using activating agent. However, ACs activated by $\mathrm{K}_{2} \mathrm{SiO}_{3}$ can be prepared in one step, which is favorable to make the steps simple and reduce energy consumption.

Presently, lignocellulosic materials are composed of sugar, which have been found to be suitable for the preparation of AC due to its low cost and high carbon content, such asZizania latifolia [11], cattail [12], lotus stalks [13], cotton stalks [14], and oil palm shell [15]. Cowhair waste $(\mathrm{CW})$, a kind of keratin waste, is abundant in tanneries, slaughterhouses, and textile factories. It has biological structures of unity and abundant keratin which provides nitrogen-containing functional groups. Converting the natural fibers into fine powders can be used into the adsorption in aqueous solution. Chen et al. have reported the characteristics of wool-based carbons activated by $\mathrm{H}_{3} \mathrm{PO}_{4}, \mathrm{ZnCl}_{2}$, and $\mathrm{K}_{2} \mathrm{CO}_{3}$ [16]. However, to our knowledge, there is no study comparing the properties of keratin and lignocellulose-based ACs activated by potassium silicate. In this sense, the main aim of this paper is to study the preparation of keratin $\mathrm{AC}$ by $\mathrm{K}_{2} \mathrm{SiO}_{3}$ activation with different preparation condition, and the 
comparison of keratin AC with lignocellulose-based ACs. Regarding the preparation method of AC, we have studied (i) how variables such as activation temperature and impregnation ratio affect the formation and properties and (ii) the effect of $\mathrm{K}_{2} \mathrm{SiO}_{3}$ on the formation of

pores. Regarding the precursors, cowhair waste (CW) and Cyperus alternifolius (CA) on developing functional groups for both ACs, textural properties of ACs were analyzed and probed.

\section{Materials and methods}

\subsection{Synthesis of the AC}

All the chemicals used in this study were analytical reagents, and deionized water was used as the experimental water. CW used in this study was obtained from a local leather factory, and cut into $5 \mathrm{~mm}$ length for further study. CA was acquired from artificial wetlands in Weishan, Shandong Province, China. Before preparing AC, CA was first washed with distilled water and then grounded into particle size in the range of $0.25-0.425 \mathrm{~mm}$.

Two different kinds of $\mathrm{ACs}$ were produced by $\mathrm{K}_{2} \mathrm{SiO}_{3}$ activation with varying impregnation ratios (IR) of 1:1-3:1 ( $\left.\mathrm{g} \mathrm{K}_{2} \mathrm{SiO}_{3}: \mathrm{g} \mathrm{CW} / \mathrm{CA}\right)$. One sample was impregnated at room temperature for $12 \mathrm{~h}$, then heated from room temperature to $105^{\circ} \mathrm{C}$ and maintained for $30 \mathrm{~min}$. The samples were placed into a tube furnace, then heated to the desired temperature $\left(400-800^{\circ} \mathrm{C}\right)$ at a same heating rate $\left(15^{\circ} \mathrm{C} / \mathrm{min}\right)$ under $\mathrm{N}_{2}$ atmosphere $(100 \mathrm{~mL} / \mathrm{min})$ and kept at that temperature for $1 \mathrm{~h}$. The ACs are referred to as CWAC-1 and CAAC-1, and the best preparation condition was determined by acquiring the properties of ACs. Thus, another mixture of $\mathrm{K}_{2} \mathrm{SiO}_{3}$ and $\mathrm{CW} / \mathrm{CA}$ with the best impregnation ratio (2:1) was only dipped for $12 \mathrm{~h}$ at room temperature, and then activated at the best temperature $\left(700^{\circ} \mathrm{C}\right)$ for $1 \mathrm{~h}$ with a heating rate of $15^{\circ} \mathrm{C} / \mathrm{min}$ in nitrogen atmosphere $(100 \mathrm{~mL} / \mathrm{min})$. The ACs are referred to as CWAC-2 and CAAC-2. After cooling down to the room temperature, carbons were washed several times with hot water to remove impurities until the $\mathrm{pH}$ value of the washing water reached nearly neutral and then dried at $105^{\circ} \mathrm{C}$ for $8 \mathrm{~h}$. Eventually, the ACs were obtained by grounding and sieving to a particle size of $100-150 \mu \mathrm{m}$ for further study.

\subsection{Characterization methods}

The thermogravimetric analyses (TGA) and derivative thermogravimetric (DTG) curves of raw materials impregnated with $\mathrm{K}_{2} \mathrm{SiO}_{3}\left(\mathrm{CW}-\mathrm{K}_{2} \mathrm{SiO}_{3}-1, \mathrm{CA}-\mathrm{K}_{2} \mathrm{SiO}_{3}-1\right)$ were evaluated by a 
SDT-simultaneous TGA-DTA model, which was operated in nitrogen atmosphere $(100 \mathrm{~mL} / \mathrm{min})$ with the heating rate of $10^{\circ} \mathrm{C}$. The mixture was heated at $105^{\circ} \mathrm{C}$ for $30 \mathrm{~min}$, then heated to $700{ }^{\circ} \mathrm{C}$ and held at this temperature for $1 \mathrm{~h}$. Other ones $\left(\mathrm{CW}-\mathrm{K}_{2} \mathrm{SiO}_{3}-2, \mathrm{CA}-\right.$ $\mathrm{K}_{2} \mathrm{SiO}_{3}-2$ ) were heated from room temperature to $700{ }^{\circ} \mathrm{C}$, and maintained at this temperature for $1 \mathrm{~h}$.

The BET specific surface area $\left(S_{\mathrm{BET}}\right)$ and pore size distribution of ACs were determined by a JW-BK122W automated surface area analyzer under nitrogen adsorption/desorption isotherm at $77 \mathrm{~K}$. The surface morphologies of ACs were captured using a Hitachi S-520 scanning electron microscope (SEM). The surface functional groups of raw materials and ACs were studied by a PerkinElmer Fourier transforms infrared (FTIR) spectrometer. The spectra were recorded in the spectral range of $4000-400 \mathrm{~cm}^{-1}$. The ACs were also characterized by X-ray diffraction (XRD) and X-ray photoelectron spectroscopy (XPS).

\section{Results and discussion}

\subsection{Results of TGA and DTG analysis}

As shown in Fig. 1, the two profiles of TGA curves for $\mathrm{CW}-\mathrm{K}_{2} \mathrm{SiO}_{3}-1$ and $\mathrm{CA}-\mathrm{K}_{2} \mathrm{SiO}_{3}-1$ are similar, and it indicates that there were four stages in the pyrolysis process. The sharp decrease of the weight loss for the two samples below $100{ }^{\circ} \mathrm{C}$ was attributed to the water loss by transpiration and partial destruction of $\mathrm{CW}-\mathrm{K}_{2} \mathrm{SiO}_{3}-1$ [3]. Because of the same reason, the weight loss of $\mathrm{CW}-\mathrm{K}_{2} \mathrm{SiO}_{3}-1$ was lower than that of $\mathrm{A}-\mathrm{K}_{2} \mathrm{SiO}_{3}-1 . \mathrm{K}_{2} \mathrm{SiO}_{3}$ can function as a dehydrating agent and react with the raw materials. The second stage at $105^{\circ} \mathrm{C}$ for $30 \mathrm{~min}$, which has a slight weight loss $\left(3.14 \%\right.$ and $4.74 \%$ for $\mathrm{CW}-\mathrm{K}_{2} \mathrm{SiO}_{3}-1$ and $\mathrm{CA}-\mathrm{K}_{2} \mathrm{SiO}_{3}-1$, respectively) corresponds to the drying and protein denaturation of the mixture. The third stage of $40-70$ min was in the range of $125-425^{\circ} \mathrm{C}$, which presents a major weight loss. The results were related to the initial forming of silicate and silicate ester, at this point, the elimination of volatile matter for both the $\mathrm{CW}$ and $\mathrm{CA}$ was the main reason. For temperature up to $700{ }^{\circ} \mathrm{C}$, the stage reflected a short decrease in weight loss as a result of the flame retardance of $\mathrm{K}_{2} \mathrm{SiO}_{3}$, and the char had a higher stable structure.

For $\mathrm{CW}-\mathrm{K}_{2} \mathrm{SiO}_{3}-2$ and $\mathrm{CA}-\mathrm{K}_{2} \mathrm{SiO}_{3}-2$, Fig. 1(a) and (c) displays that both of them have three phases which differed from that of $\mathrm{CW}-\mathrm{K}_{2} \mathrm{SiO}_{3}-1$ and $\mathrm{CA}-\mathrm{K}_{2} \mathrm{SiO}_{3}-1$ due to the missing constant temperature at $105{ }^{\circ} \mathrm{C}$. Thus, the weight losses for $\mathrm{CW}-\mathrm{K}_{2} \mathrm{SiO}_{3}-1$ and $\mathrm{CA}-$ 
$\mathrm{K}_{2} \mathrm{SiO}_{3}-1$ were higher than $\mathrm{CW}-\mathrm{K}_{2} \mathrm{SiO}_{3}-2$ and $\mathrm{CA}-\mathrm{K}_{2} \mathrm{SiO}_{3}-2$, respectively. This difference may be caused by the long heating time. Compared to $\mathrm{CW}-\mathrm{K}_{2} \mathrm{SiO}_{3}, \mathrm{CA}-\mathrm{K}_{2} \mathrm{SiO}_{3}$ represented higher mass percent, which was attributed to the higher carbon content of cellulosic biomass and the higher volatilization of organic matter for keratin materials at high temperature. As can be seen in the dramatically decomposed process, DTG curves present a maximum peak at 74.7 and $91.2{ }^{\circ} \mathrm{C}$ for $\mathrm{CW}-\mathrm{K}_{2} \mathrm{SiO}_{3}$ and $\mathrm{CA}-\mathrm{K}_{2} \mathrm{SiO}_{3}$, respectively, and the peak intensity of profiles follows such a regular pattern: $\mathrm{CW}-\mathrm{K}_{2} \mathrm{SiO}_{3}>\mathrm{CA}-\mathrm{K}_{2} \mathrm{SiO}_{3}$. It suggests that $\mathrm{CW}$ had great changes at this temperature compared with $\mathrm{CA}$, which can be interpreted that $\mathrm{CW}$ would be modified with $\mathrm{K}_{2} \mathrm{SiO}_{3}$ as the activating agent under the temperature. However, as lignocellulose material, the decomposition temperature of $\mathrm{CA}$ was about $300{ }^{\circ} \mathrm{C}$ [17]. $\mathrm{CW}-$ $\mathrm{K}_{2} \mathrm{SiO}_{3}$ had no obvious peaks as the temperature increased.
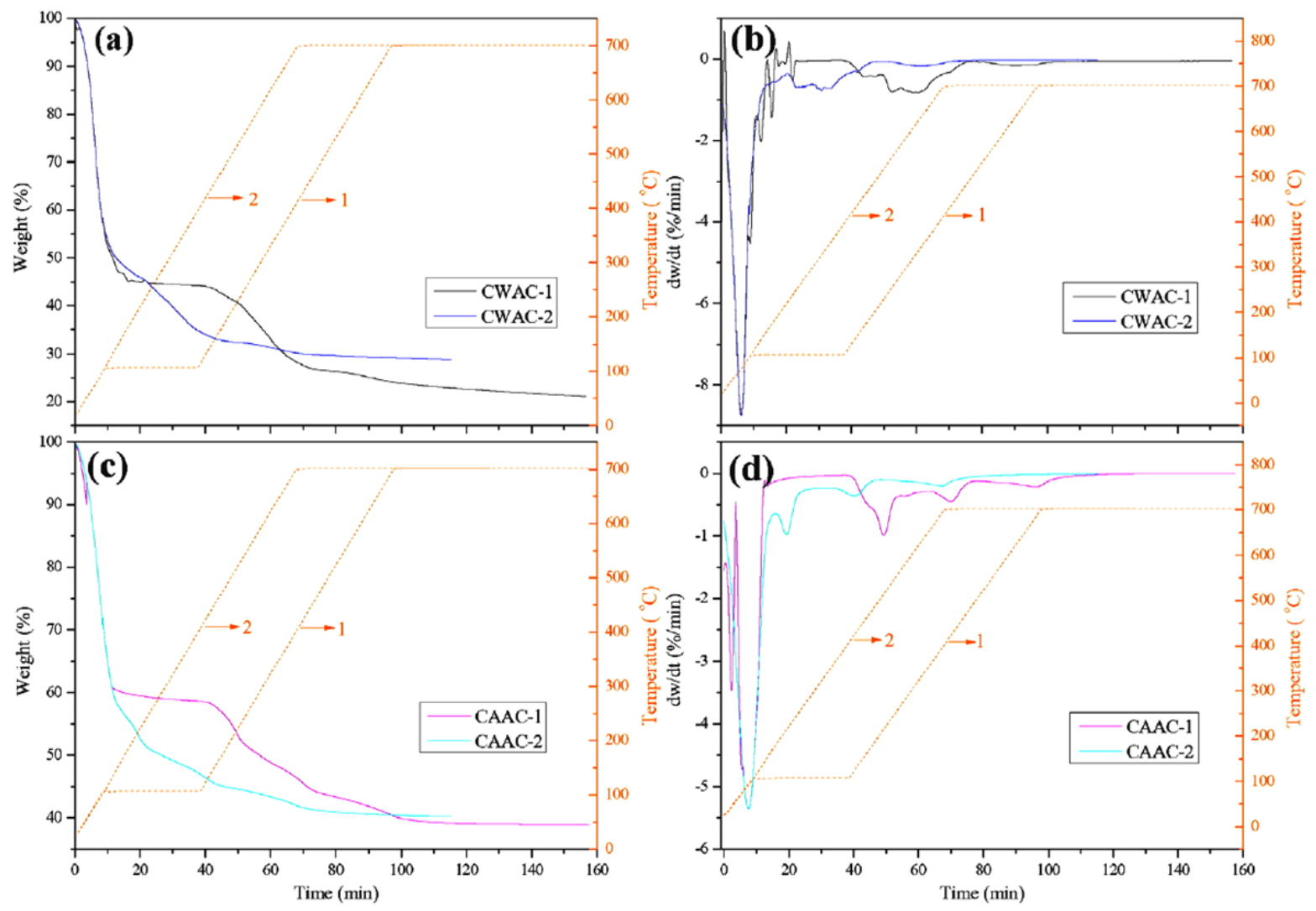

Fig. 1. TGA and DTG diagrams for $\mathrm{CW}-\mathrm{K}_{2} \mathrm{SiO}_{3}$ and $\mathrm{CA}-\mathrm{K}_{2} \mathrm{SiO}_{3}$ in $\mathrm{N}_{2}$ atmosphere.

\subsection{Porosity of ACs}

\subsubsection{Effects of activation temperature}

In the activation, the final activation temperature and impregnation ratio play an important role in determining the porous properties. $\mathrm{CW}$ or $\mathrm{CA}$ was mixed with $\mathrm{K}_{2} \mathrm{SiO}_{3}$ at a certain IR 
under varying temperatures to obtain the resultant AC. Table 1 indicates that the specific area $\left(S_{\mathrm{BET}}\right)$, micropore surface area $\left(S_{\mathrm{mic}}\right)$, pore volume $\left(V_{\mathrm{tot}}\right)$ and micropore volume $\left(V_{\mathrm{mic}}\right)$ of $\mathrm{CWAC}$ increased when the temperature ranged from $400{ }^{\circ} \mathrm{C}$ to $800{ }^{\circ} \mathrm{C}$, and then decreased with the temperature. The maximum $S_{\mathrm{BET}}, S_{\text {mic }}, V_{\text {tot }}$ and $V_{\text {mic }}$ could reach to $1965 \mathrm{~m}^{2} / \mathrm{g}$, $1462 \mathrm{~m}^{2} / \mathrm{g}, 1.345 \mathrm{~cm}^{3} / \mathrm{g}$ and $0.7954 \mathrm{~cm}^{3} / \mathrm{g}$, respectively. The phenomenon could be due to the release of volatile matter and the corrosion of $\mathrm{K}_{2} \mathrm{SiO}_{3}$. When the activation temperature was low, the role of $\mathrm{K}_{2} \mathrm{SiO}_{3}$ was weak and only the raw material was carbonized. $\mathrm{K}_{2} \mathrm{SiO}_{3}$ started to promote the opening of micropores as the temperature increased from $400{ }^{\circ} \mathrm{C}$ to $700{ }^{\circ} \mathrm{C}$. Meanwhile the quantity of generated new pores was more than the etching ones, thus the specific area and pore volume of the final products increased. The carbon prepared at $500{ }^{\circ} \mathrm{C}$ had a higher micropore volume ratio (84.18\%), illustrating that abundant micropores were open and the corrosive effect was weak. However, when the temperature was high, partial micropores can be merged into mesopores or macropores as a result of corrosion and volatile matters [18]. In addition, the volatilization of carbon atom on crystalline layers was intensified. As shown in Table 1 , the carbons produced at $500{ }^{\circ} \mathrm{C}, 600^{\circ} \mathrm{C}$ and $700{ }^{\circ} \mathrm{C}$ mainly contained micropore structures. Table 2 shows the parameters of surface area and pore volume for CAAC. The tendency of results was similar to the data in Table 1.

Table 1. Surface areas and pore volume of ACs produced by CW under different conditions.

\begin{tabular}{lllllllll}
\hline AC & $\begin{array}{l}\text { Activation } \\
\text { temperatu } \\
\text { re }\end{array}$ & $\begin{array}{l}\text { Impregn } \\
\text { ation } \\
\text { ratio }\end{array}$ & $S_{\text {BET }}$ & $S_{\text {mic }}$ & $V_{\text {tot }}$ & $V_{\text {mic }}$ & $\boldsymbol{V}_{\text {mic }} / \boldsymbol{V}_{\text {tot }}$ & $\boldsymbol{D}_{\mathbf{P}}$ \\
\cline { 2 - 4 } & $\left({ }^{\circ} \mathrm{C}\right)$ & $(\mathrm{IR})$ & $\left(\mathrm{m}^{2} / \mathrm{g}\right)$ & $\left(\mathrm{m}^{2} / \mathrm{g}\right)$ & $\left(\mathrm{cm}^{3} / \mathrm{g}\right)$ & $\left(\mathrm{cm}^{3} / \mathrm{g}\right)$ & $(\%)$ & $(\mathrm{nm})$ \\
& 400 & $2: 1$ & 8 & & 0.072 & 0.0024 & 3.33 & 14.749 \\
& 500 & $2: 1$ & 657 & 632 & 0.337 & 0.2837 & 84.18 & 2.046 \\
& 600 & $2: 1$ & 802 & 707 & 0.494 & 0.315 & 63.77 & 2.460 \\
& 700 & $2: 1$ & 1965 & 1462 & 1.345 & 0.7954 & 59.14 & 2.646 \\
& 800 & $2: 1$ & 4 & & 0.039 & 0.0016 & 4.10 & 35.617 \\
& 700 & $1: 1$ & 33 & 25 & 0.099 & 0.0109 & 11.01 & 10.005 \\
& 700 & $1.5: 1$ & 1566 & 1466 & 0.855 & 0.6609 & 77.30 & 2.145 \\
& 700 & $2: 1$ & 1965 & 1462 & 1.345 & 0.7954 & 59.14 & 2.646 \\
& 700 & $2.5: 1$ & 1820 & 1489 & 1.176 & 0.7462 & 63.45 & 2.488 \\
& 700 & $3: 1$ & 339 & 205 & 0.594 & 0.1373 & 23.11 & 6.980 \\
\hline \multirow{2}{*}{ CWAC-2 } & & & 419 & 269 & 0.394 & 0.162 & 41.12 & 3.649 \\
\hline
\end{tabular}


Table 2. Surface areas and pore volume of AC produced by CA under different conditions.

\begin{tabular}{|c|c|c|c|c|c|c|c|c|}
\hline \multirow[t]{2}{*}{ AC } & $\begin{array}{l}\text { Activation } \\
\text { temperature }\end{array}$ & $\begin{array}{l}\text { Impregnation } \\
\text { ratio }\end{array}$ & $S_{\mathrm{BET}}$ & $S_{\text {mic }}$ & $V_{\text {tot }}$ & $V_{\text {mic }}$ & $V_{\text {mic }} / V_{\text {tot }}$ & $D_{\mathbf{P}}$ \\
\hline & $\left({ }^{\circ} \mathrm{C}\right)$ & (IR) & $\left(\mathrm{m}^{2} / \mathrm{g}\right)$ & $\left(\mathrm{m}^{2} / \mathrm{g}\right)$ & $\left(\mathrm{cm}^{3} / \mathrm{g}\right)$ & $\left(\mathrm{cm}^{3} / \mathrm{g}\right)$ & $(\%)$ & $(\mathrm{nm})$ \\
\hline \multirow[t]{5}{*}{ CAAC } & 400 & $2: 1$ & 79 & & 0.217 & 0.0329 & 15.16 & 10.904 \\
\hline & 500 & $2: 1$ & 586 & 486 & 0.543 & 0.2533 & 46.65 & 3.710 \\
\hline & 600 & $2: 1$ & 888 & 837 & 0.549 & 0.3881 & 70.69 & 2.473 \\
\hline & 700 & $2: 1$ & 1710 & 1575 & 0.949 & 0.7376 & 77.72 & 2.212 \\
\hline & 800 & $2: 1$ & 907 & 810 & 0.704 & 0.3943 & 56.01 & 3.099 \\
\hline \multirow[t]{5}{*}{ CAAC } & 700 & $1: 1$ & 1391 & 1219 & 0.899 & 0.6013 & 66.88 & 2.595 \\
\hline & 700 & $1.5: 1$ & 1582 & 1238 & 1.391 & 0.6756 & 48.57 & 3.498 \\
\hline & 700 & $2: 1$ & 1710 & 1576 & 0.949 & 0.7376 & 77.72 & 2.212 \\
\hline & 700 & $2.5: 1$ & 1990 & 1888 & 1.137 & 0.8667 & 76.23 & 2.177 \\
\hline & 700 & $3: 1$ & 2185 & 1918 & 1.408 & 0.9309 & 66.11 & 2.537 \\
\hline $\begin{array}{l}\text { CAAC- } \\
2\end{array}$ & & & 1682 & 1437 & 1.152 & 0.7182 & 62.34 & 2.721 \\
\hline
\end{tabular}

According to the International Union of Pure and Applied Chemistry (IUPAC), pores can be classified into three categories: micropore (diameter $<2 \mathrm{~nm}$ ); mesopore $(2 \mathrm{~nm}<$ diameter $<50 \mathrm{~nm})$; and macropore (diameter $>50 \mathrm{~nm})$. Fig. 2(a) illustrates that ACs $\left(\mathrm{CWAC} / 500{ }^{\circ} \mathrm{C}(2: 1), \mathrm{CWAC} / 600{ }^{\circ} \mathrm{C}(2: 1)\right.$, and $\left.\mathrm{CWAC} / 700{ }^{\circ} \mathrm{C}(2: 1)\right)$ had a higher inflection point and $\mathrm{N}_{2}$ adsorption capacity than $\mathrm{CWAC} / 400{ }^{\circ} \mathrm{C}(2: 1)$ and $\mathrm{CWAC} / 800{ }^{\circ} \mathrm{C}(2: 1)$. $\mathrm{CWAC} / 700{ }^{\circ} \mathrm{C}(2: 1)$ was the best $\mathrm{AC}$ with the highest surface area and $\mathrm{N}_{2}$ adsorption capacity. Fig. 3(a) also shows the same trend in the $\mathrm{N}_{2}$ adsorption/desorption isotherm. Furthermore, the five carbons had hysteresis loops, all the data illustrate that the former three carbons followed the mixture of reversible types I and IV isotherms [19]. Thus the pores mainly contained both micropores and mesopores, and micropores were the primary form. Fig. 2(a) and (b) displays that the majority of pores were in the range of $1-4 \mathrm{~nm}$, indicating a micro-mesopore structure, which conforms with the above conclusion. 

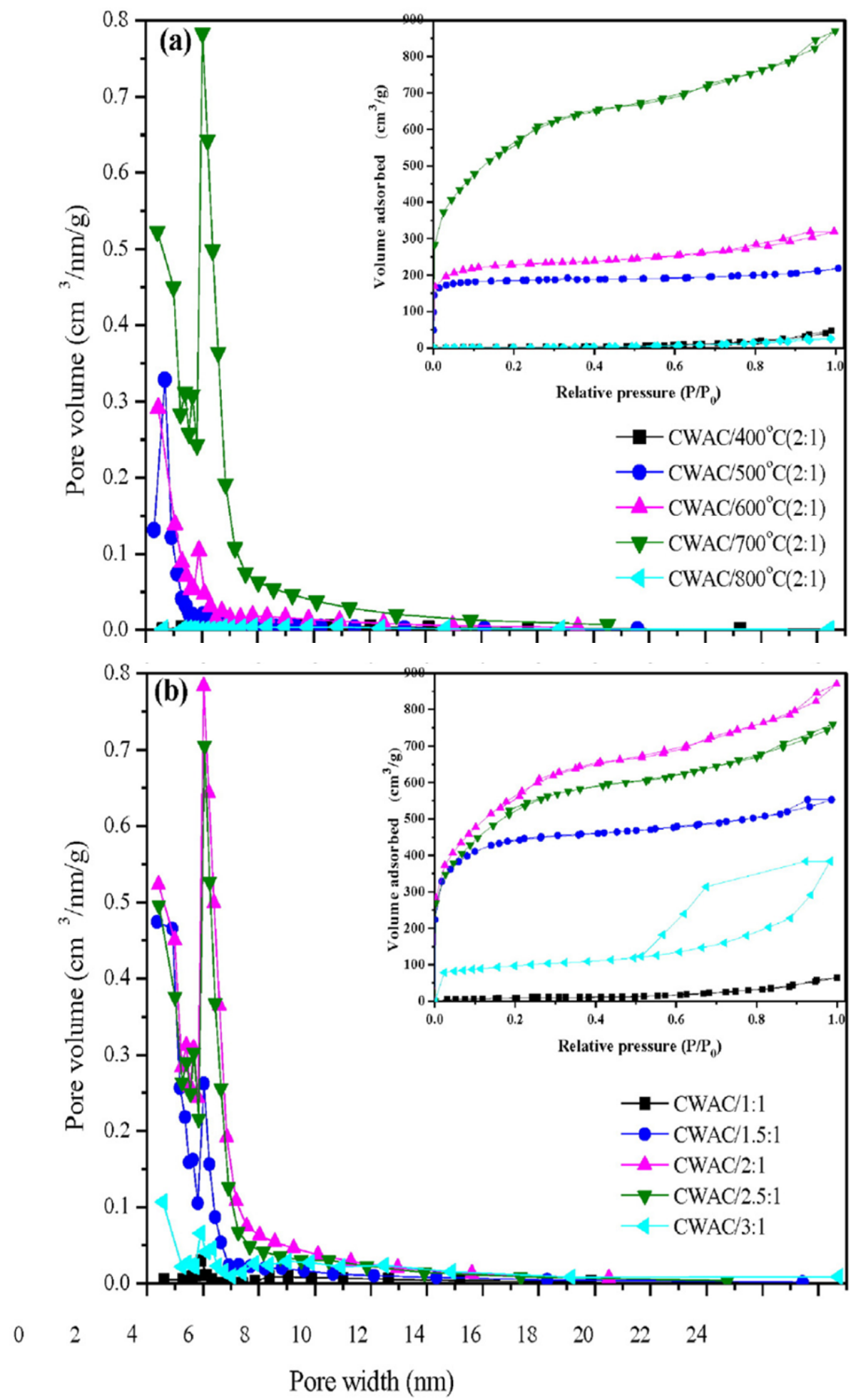

Fig. 2. Pore size distribution and nitrogen adsorption/desorption isotherms (inset) of CWACs at $700{ }^{\circ} \mathrm{C}$. 

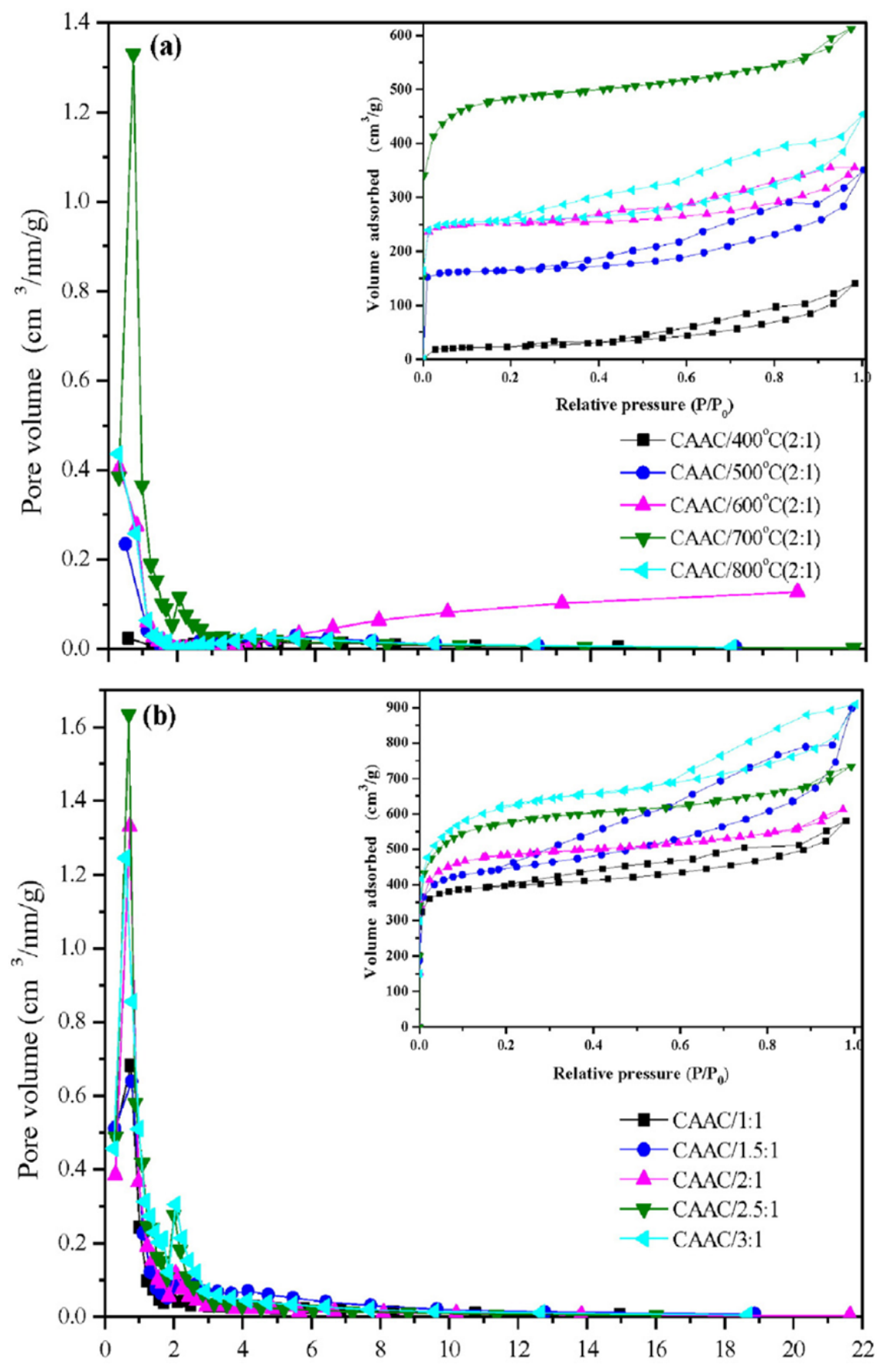

Pore width (mm)

Fig. 3. Pore size distribution and nitrogen adsorption/desorption isotherms (inset) of CAACs at $700{ }^{\circ} \mathrm{C}$.

\subsubsection{Effects of $\mathrm{K}_{2} \mathrm{SiO}_{3}$ /precursor weight ratio}

The activating agent/precursor is a significant factor and was chosen for the next study [20]. ACs produced at the final activation temperature of $700{ }^{\circ} \mathrm{C}$ with varying impregnation ratios 
(1:1-3:1) were discussed. Table 1 indicates that the surface area and pore volume increased as the impregnation ratio increased from $1: 1$ to $2: 1$, then decreased with the impregnation ratio, illustrating that $\mathrm{CWAC}$ attained its best state when the impregnation ratio was $2: 1$. The phenomenon can be explained by the well-developed micropore that was formed with the reaction of $\mathrm{K}_{2} \mathrm{SiO}_{3}$ and protein ingredient. However, when the impregnation ratio was more than $2: 1$, the excess $\mathrm{K}_{2} \mathrm{SiO}_{3}$ would react with the carbon around the porosity and the micropores were eroded thereby the pores were widened [21] and [22]. Moreover, the number of generated micropores was lower than that of the micropores' correlation, which led to the BET surface area being increased. As Fig. 2(b) shows, all the isotherms follow the same trend and the hysteresis loops existed, illustrating the existence of large micropores and mesopores [23]. Moreover, the carbon activated at $700{ }^{\circ} \mathrm{C}$ with the impregnation ratio of 2:1 had the largest $\mathrm{N}_{2}$ adsorption capacity, and it increased with the BET surface area.

Table 2 shows that the BET surface area $\left(S_{\mathrm{BET}}\right)$ and micropore surface area $\left(S_{\text {mic }}\right)$ of CAAC increased with the impregnation ratio from $1: 1$ to $3: 1$. It is different from the phenomenon about CWAC. Meanwhile, Fig. 3(b) reveals that the obvious hysteresis loops existed when IR was $1: 1,1.5: 1$, and $3: 1$ at $700^{\circ} \mathrm{C}$; the quantity of mesopores decreased with the impregnation ratio then increased, as shown by the data of $V_{\text {mic }} / V_{\text {totand }} D_{\mathrm{P}}$ in Table 2.

\subsubsection{Effects of the pre-process}

Both of the CWAC and CAAC activated at $700{ }^{\circ} \mathrm{C}$ with the IR of 2:1 were chosen for the next study, and the effect of pre-process namely heating at $105{ }^{\circ} \mathrm{C}$ for $30 \mathrm{~min}$ was discussed. Table 1 shows that CWAC-1 had higher specific surface area $\left(S_{\mathrm{BET}}\right)$, micropore surface area $\left(S_{\text {mic }}\right)$, pore volume $\left(V_{\text {tot }}\right)$, and micropore volume $\left(V_{\text {mic }}\right)$ than CWAC-2, indicating that CWAC-1 was mainly a microporous structure and CWAC-2 had large number of mesopores. The pre-process had a remarkable influence on $\mathrm{CWAC}-1$ since the $\mathrm{CW}$ can be completely impregnated in the $\mathrm{K}_{2} \mathrm{SiO}_{3}$ solution. However, partly precursor for CWAC-2 was carbonized due to the incomplete impregnation, producing the macropores and mesopores. Table 2 indicates that the effect of pre-process did not had much influence on the surface area of CAAC-1, illustrating that the room temperature impregnation has excellent role to the impregnation effect. The proportion of mesopores for CAAC-2 was high, indicating that the pre-process was favorable for the formation of micropores.

As presented in Fig. 4, the curves of both CWAC-1 and CWAC-2 had short hysteresis loop. According to the types of the isotherms, CWAC-1 and CWAC-2 were mainly 
microporous structures. Obviously, the nitrogen adsorption capacity of CWAC-1 was nearly four times than that of CWAC-2, which also illustrates that CWAC has developed pore structure further. Table 2 compiles that CAAC-2 had more micropores and less mesopores than CAAC-2, which was also shown by the nitrogen adsorption/desorption isotherms in Fig. 4. Fig. 4 presents that most of the pores were less than $4 \mathrm{~nm}$. In general, compared with CWAC-2, CWAC-1 was mainly microporous; CWAC-1 as well as CWAC-2 had structures of micropores and mesopores, respectively. As listed in Table 3, the surface area of ACs in this study is higher than that of ACs prepared by different activating agents. AC activated by $\mathrm{KOH}$ possesses $S_{\mathrm{BET}}$ and $V_{\text {tot }}$ as high as $2118 \mathrm{~m}^{2} / \mathrm{g}$ and $1.14 \mathrm{~cm}^{3} / \mathrm{g}$ [20], while CAAC can reach to $2180 \mathrm{~m}^{2} / \mathrm{g}$ of $\mathrm{S}_{\mathrm{BET}}$ and $1.408 \mathrm{~cm}^{3} / \mathrm{g}$ of $V_{\text {tot }}$. According to the results, $\mathrm{K}_{2} \mathrm{SiO}_{3}$ can be considered as a promising activating agent for AC preparation.

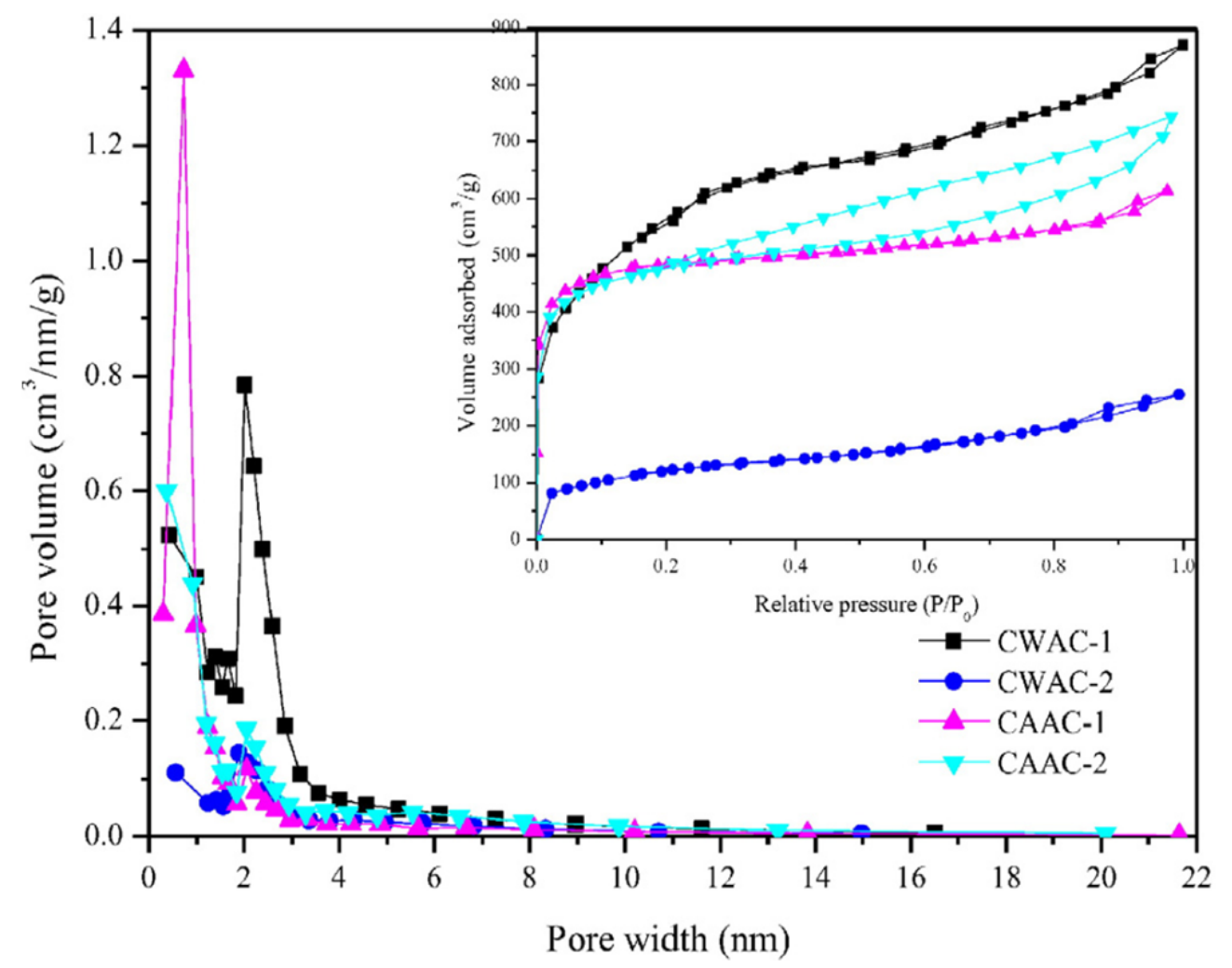

Fig. 4. Pore size distribution and nitrogen adsorption/desorption isotherms (inset) of CWAC and CAAC.

All the above data confirmed that carbon activated by potassium silicate had different porous structures compared with carbons activated with other activating agents. It is clear that (i) the three variables affect the final results; (ii) different precursors had a great influence on the 
pores of resulting carbons and the trend was different; (iii) for CA, increasing the impregnation ratio benefited for the development of BET specific surface area; (iv) the pretreatment process played an important role in the preparation of $\mathrm{CWAC}$, but has a weak influential role for that of CAAC.

Table 3. Comparison of surface area of ACs prepared from different activating agents.

\begin{tabular}{llll}
\hline Precursor & Activating agent & $\boldsymbol{S}_{\text {BET }}\left(\mathbf{m}^{2} / \mathbf{g}\right)$ & Reference \\
\hline Palm oil & $\mathrm{CO}_{2}$ & 1100 & {$[24]$} \\
Leather waste & $\mathrm{Steam}$ & 493.5 & {$[23]$} \\
Grape stalk & $\mathrm{ZnCl}_{2}$ & 1411 & {$[6]$} \\
Hemp bast & $\mathrm{H}_{3} \mathrm{PO}_{4}$ & 1142.4 & {$[25]$} \\
Arundo donax Linn. & $\mathrm{H}_{4} \mathrm{P}_{2} \mathrm{O}_{7}$ & 1463 & {$[26]$} \\
Algae meal & $\mathrm{KOH}$ & 2118 & {$[20]$} \\
Grape seed & $\mathrm{K}_{2} \mathrm{CO}_{3}$ & 1238 & {$[27]$} \\
CW & $\mathrm{K}_{2} \mathrm{SiO}_{3}$ & 1965 & This study \\
CA & $\mathrm{K}_{2} \mathrm{SiO}_{3}$ & 2185 & This study \\
\hline
\end{tabular}

\subsection{SEM analysis of the ACs}

As indicated in Fig. 5(a, b), the basic structure of the starting materials was obviously different. $\mathrm{CW}$ had rough surface and stick shape while CA represented the appearance of cellulose fibers. Depending on the precursor used, the ACs had different pore sizes and pore shapes between cellulose fiber and keratin waste based carbons. Because of the consumption of oxygen in the $\mathrm{N}_{2}$ atmosphere, the surface was smooth [2]. Fig. 5(c-f) shows that the raw materials were corroded and all the carbons were occupied by varieties of pores, meanwhile the pores were interconnected.

The pores of CWAC were relatively uniform while CAAC had both large and little pores. After the pre-treatment of heating at $105^{\circ} \mathrm{C}, \mathrm{CWAC}-1$ had well-developed pores, thus possessed high BET surface area. The pores in CWAC-2 were eroded severely, micropores or mesopores enlarged into macropores inducing low surface area and total volume, as shown by the results of pore analysis. For CAAC-2, it did not had much difference with CAAC-1, namely the pre-treatment had little changes for the preparation of ACs. In the activation process, the presence of $\mathrm{K}_{2} \mathrm{SiO}_{3}$ contributed to the formation of pores especially for the micropores and was favorable to the surface area. The images of ACs show that the raw 
materials changed widely. The main reason for the existence of white dots on the surface of the carbons was that the chemical organic gases deposed during this process.

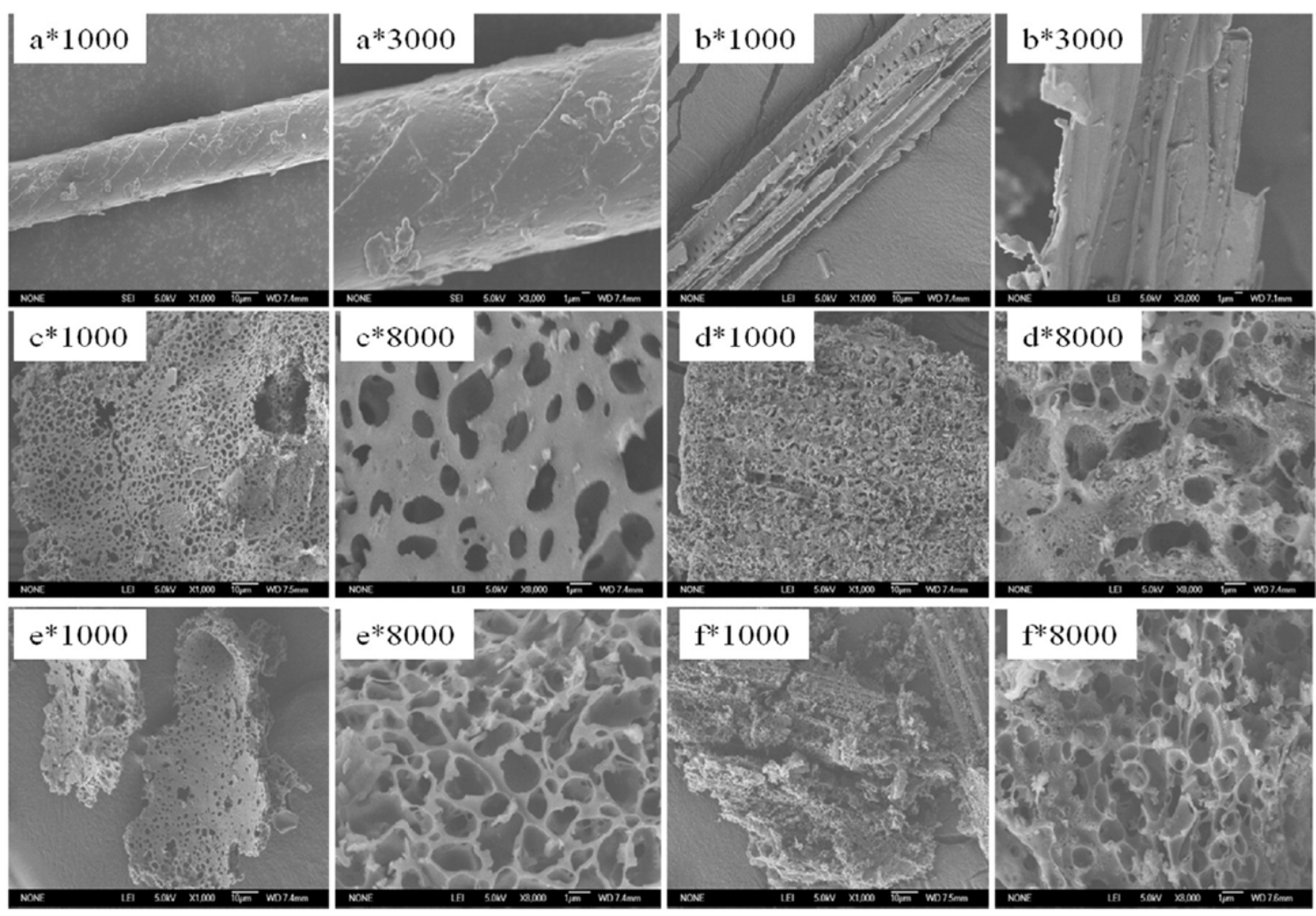

Fig. 5. SEM micrographs of CW (a), CA (b), CWAC-1 (c), CWAC-2 (d), CAAC-1 (e), and CAAC-2 (f) at different magnifications $(1000 \times, 3000 \times$, and $8000 \times)$.

\subsection{FT-IR and XPS analyses}

As seen in Fig. 6, CAAC had small amount of functional groups, indicating that the activation of keratin waste with $\mathrm{K}_{2} \mathrm{SiO}_{3}$ was favorable for the formation of functional groups than that of lignocelluloses.

The spectrum reveals that there was a broad band in the range of 3100$3700 \mathrm{~cm}^{-1}$ with a maximum at about $3428.60 \mathrm{~cm}^{-1}$. The characteristic peak was the stretching vibration of hydroxyl, indicating a high degree of association due to the existence of hydrogen bond [28]; CWAC had the greater broad band than CAAC. The band at $1624.21 \mathrm{~cm}^{-1}$ was the $-\mathrm{NH}-$ stretching in $-\mathrm{CONH}-$ for all the carbons especially $\mathrm{CWAC}$, displaying large amounts of nitrogen functional groups emerged on the surface of CWAC. For both CWAC-1 and CWAC-2, the band located around $1040 \mathrm{~cm}^{-1}$ was attributed to the 
stretching vibration of $\mathrm{Si}-\mathrm{N}$. The reason was that the protein materials were activated by $\mathrm{K}_{2} \mathrm{SiO}_{3}$ and the $\mathrm{Si}-\mathrm{N}$ bond formed. The peak at $1080.34 \mathrm{~cm}^{-1}$ for CWAC-1 was assigned to the antisymmetric stretching vibration of $\mathrm{Si}-\mathrm{O}$; however, the band disappeared for CWAC-2 without the pre-treatment of heating.

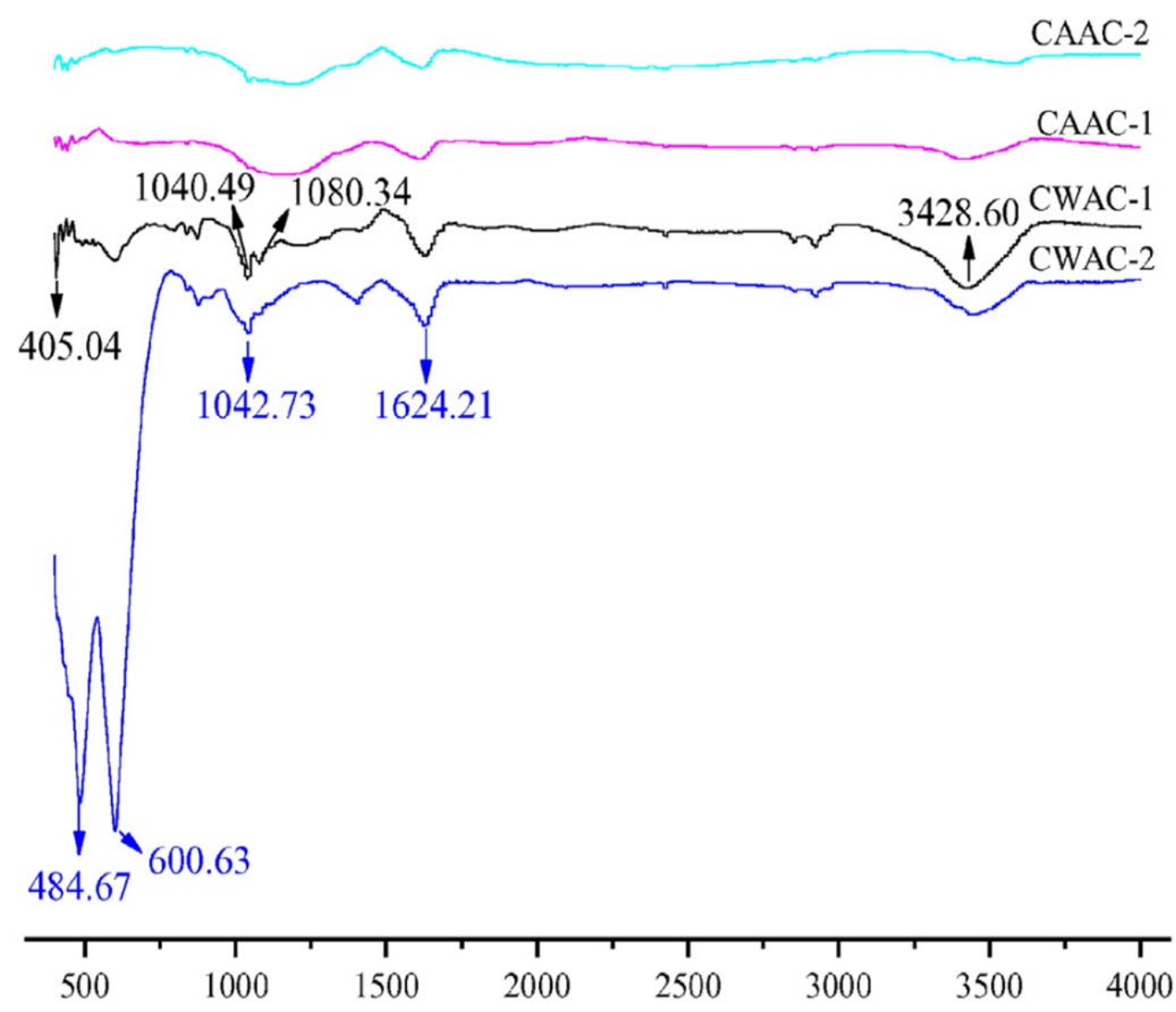

Fig. 6. FTIR spectra of CWAC-1, CWAC-2, CAAC-1, and CAAC-2.

There were no apparent peaks for CAAC in FT-IR; therefore, the functional groups of CW, CWAC-1, and CWAC-2 were analyzed by XPS. XPS analysis was used to determine the functional groups further. The survey spectra in Fig. 7(f) illustrate that there are some obvious peaks: C 1s, O 1s, and N 1s, but the peak of Si 2p 3/2 was low, which stated that the carbons had small amount of Si. The $\mathrm{N}$ 1s spectra of $\mathrm{CW}$ had several kinds of nitrogen species by deconvolution. The peak at $396.42 \mathrm{eV}$ can be described to be nitride-like species or imines in aromatic compounds. Meanwhile, the interpretation of peak at $397.77 \mathrm{eV}$ can be attributed to pyridine structure, amine or pyrrolic compounds [29]. However, after activation, AC shows a distinct difference. The $\mathrm{N}$ 1s of CWAC-1 and CWAC-2 fitted three curves: $\mathrm{N}-\mathrm{H}$ 
(398.28-398.75 eV); -CONH- (400.13-400.38 eV); and C-N (401.25-402.32 eV) [29]. Activation induced high content of $-\mathrm{CONH}-$ functional groups, which can be confirmed by the FTIR spectra. In the case of Si, high-resolution XPS spectrum of Si 2p 3/2 for CWAC-1 was resolved into two peaks: silicon in silicon nitride $(101.58 \mathrm{eV})$ and silicon in silicate $(102.68 \mathrm{eV})$. The XPS spectrum of Si 2p 3/2 for CWAC-2 was fitted into three curves: silicon in $\mathrm{SiC}(100.24 \mathrm{eV})$; silicon in $\mathrm{Si}_{3} \mathrm{~N}_{4}(101.62 \mathrm{eV})$; and silicon in silicate $(102.40 \mathrm{eV})$. It has been demonstrated that silicon in silicate interacted with nitrogen or carbon, thus the chemical covalent bonding formed.

As indicated in Fig. 8, the C 1s spectra of CWAC-1 and CWAC-2 can each be fitted to three peaks [30] and [31]: $\mathrm{C}-\mathrm{H}$ or $\mathrm{C}-\mathrm{C}(284.55-284.63 \mathrm{eV}) ; \mathrm{C}-\mathrm{O}$ in phenol, alcohol, or ether $(285.31-285.65 \mathrm{eV})$; and $\mathrm{O}-\mathrm{CO}$ or $-\mathrm{CO}(288.26-288.38 \mathrm{eV})$. However, the $\mathrm{C} 1 \mathrm{~s}$ spectrum of CW was fitted to two peaks, which include carbon in carbide $(281.50 \mathrm{eV})$ and carbon in $\mathrm{C}-\mathrm{H}$ or $\mathrm{C}-\mathrm{C}(284.52 \mathrm{eV})$. It is suggested that the role of $\mathrm{K}_{2} \mathrm{SiO}_{3}$ enhanced the generation of $\mathrm{C}$-containing functional groups, as shown in the FTIR results. The $\mathrm{O}$ 1s spectra of $\mathrm{CWAC}-1$ and $\mathrm{CWAC}-2$ were fitted to three curves: $\mathrm{CO}$ in anhydride, carboxylate or ester/ketone $(530.23-530.35 \mathrm{eV})$; $\mathrm{CO}$ in fatty acid $(531.20-531.31 \mathrm{eV})$; and $\mathrm{C}-\mathrm{OH}$ or $\mathrm{C}-\mathrm{O}-$ $\mathrm{C}$ in phenol/ester/amide/anhydride (531.98-532.65 eV) [31] and [32]. As seen, the functional groups of $\mathrm{CO}$ increased after activation.

\subsection{XRD analysis}

The XRD was performed to study the structure of ACs produced by keratin waste and lignocelluloses under different conditions. Fig. 9 shows that there was a diffraction peak at around $2 \theta=25^{\circ}$ for $\mathrm{CW}$ which was dramatically different from CA, which can be explained that CA had the microcrystalline structure of cellulose [17] and the structure of aromatic layers was stacked [33]. After the activation with $\mathrm{K}_{2} \mathrm{SiO}_{3}$, diffraction peak at around $2 \theta=25^{\circ}$

for CAAC was weak, meanwhile, the CWAC-1 and CAAC-2 had no apparent characteristic peaks of crystallinity, indicating an amorphous carbon. The keratin AC without pretreatment (CWAC-2) represents that there were two diffraction peaks at $2 \theta=35.22^{\circ}$ and $62.30^{\circ}$, which are corresponding to the interlayer spacing of $0.2548 \mathrm{~nm}$ and $0.1490 \mathrm{~nm}$, respectively. However, the resulting lignocelluloses based ACs reflected different patterns. CAAC-1 had a prominent peak at $27.49^{\circ}$ with the interlayer spacing of $0.3245 \mathrm{~nm}$. All the interlayer spacing data were lesser than those of graphite, $0.335 \mathrm{~nm}$, illustrating non-graphite carbons [34]. In 
conclusion, Fig. 9 illustrates that the raw materials and resulting ACs had no crystal structure and were amorphous materials.

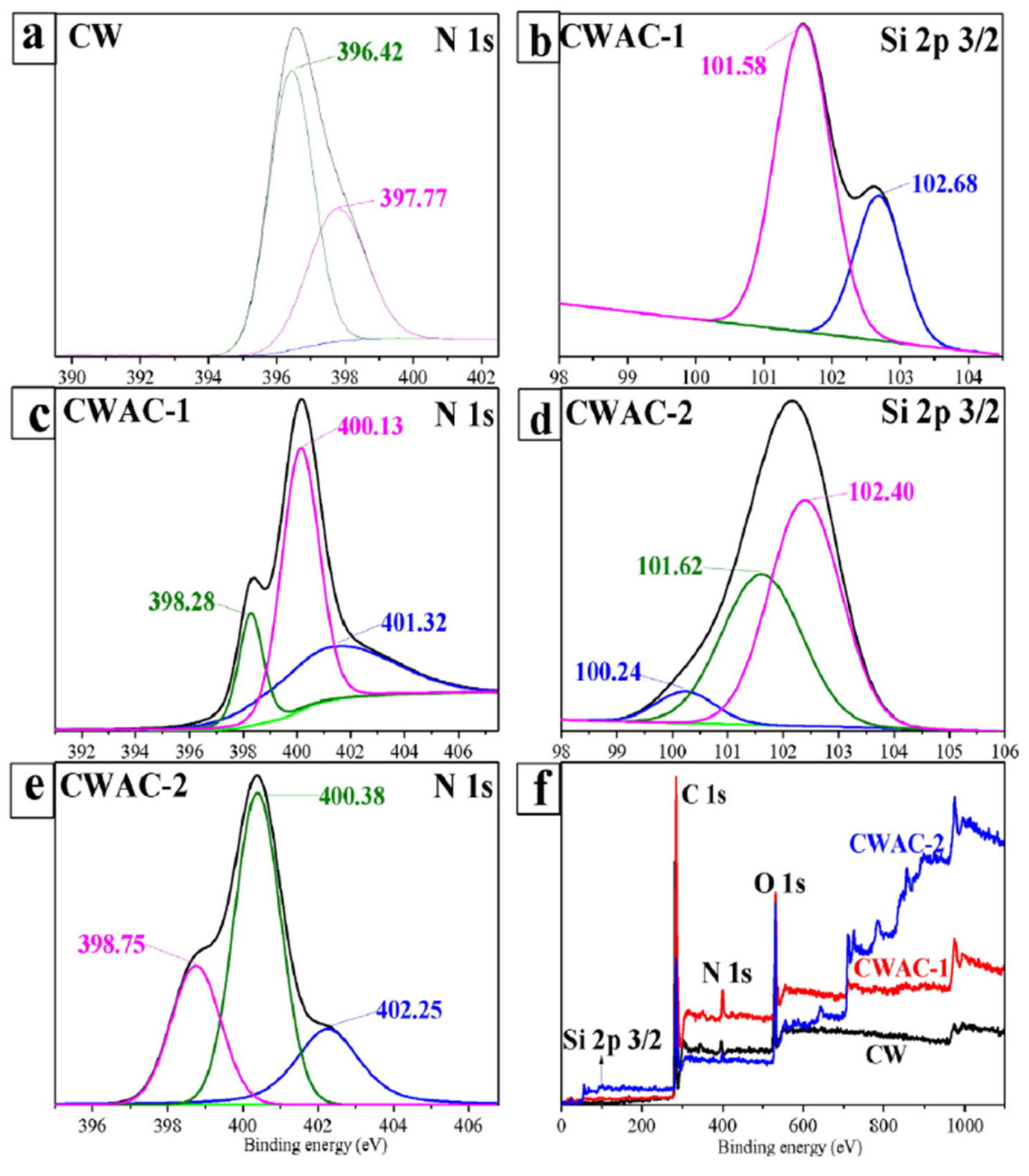

Fig. 7. XPS spectra of CW and CWAC: N 1s of CW (a); Si 2p 3/2 of CWAC-1 (b); N 1s of CWAC-1 (c); Si 2p 3/2 of CWAC-2 (d); N 1s of CWAC-2 (e); survey scanning spectra of $\mathrm{CW}, \mathrm{CWAC}-1$ and $\mathrm{CWAC}-2$ (f). 

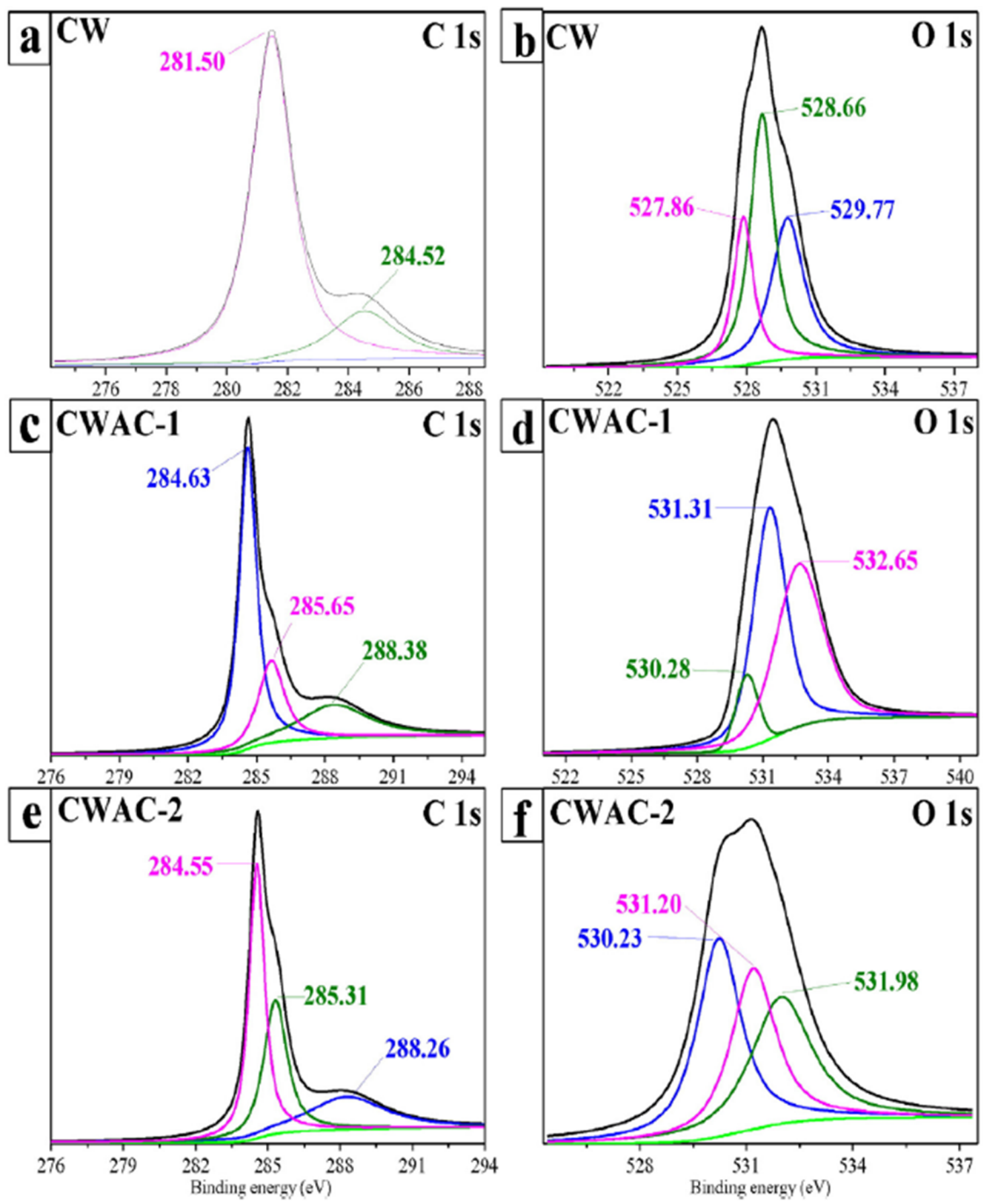

Fig. 8. XPS spectra of $\mathrm{CW}$ and $\mathrm{CWAC}$ : $\mathrm{C} 1 \mathrm{~s}$ of $\mathrm{CW}(\mathrm{a})$; O 1s of $\mathrm{CW}(\mathrm{b})$; $\mathrm{C}$ 1s of CWAC-1 (c); O 1s of CWAC-1 (d); C 1s of CWAC-2 (e); O 1s of CWAC-2 (f). 

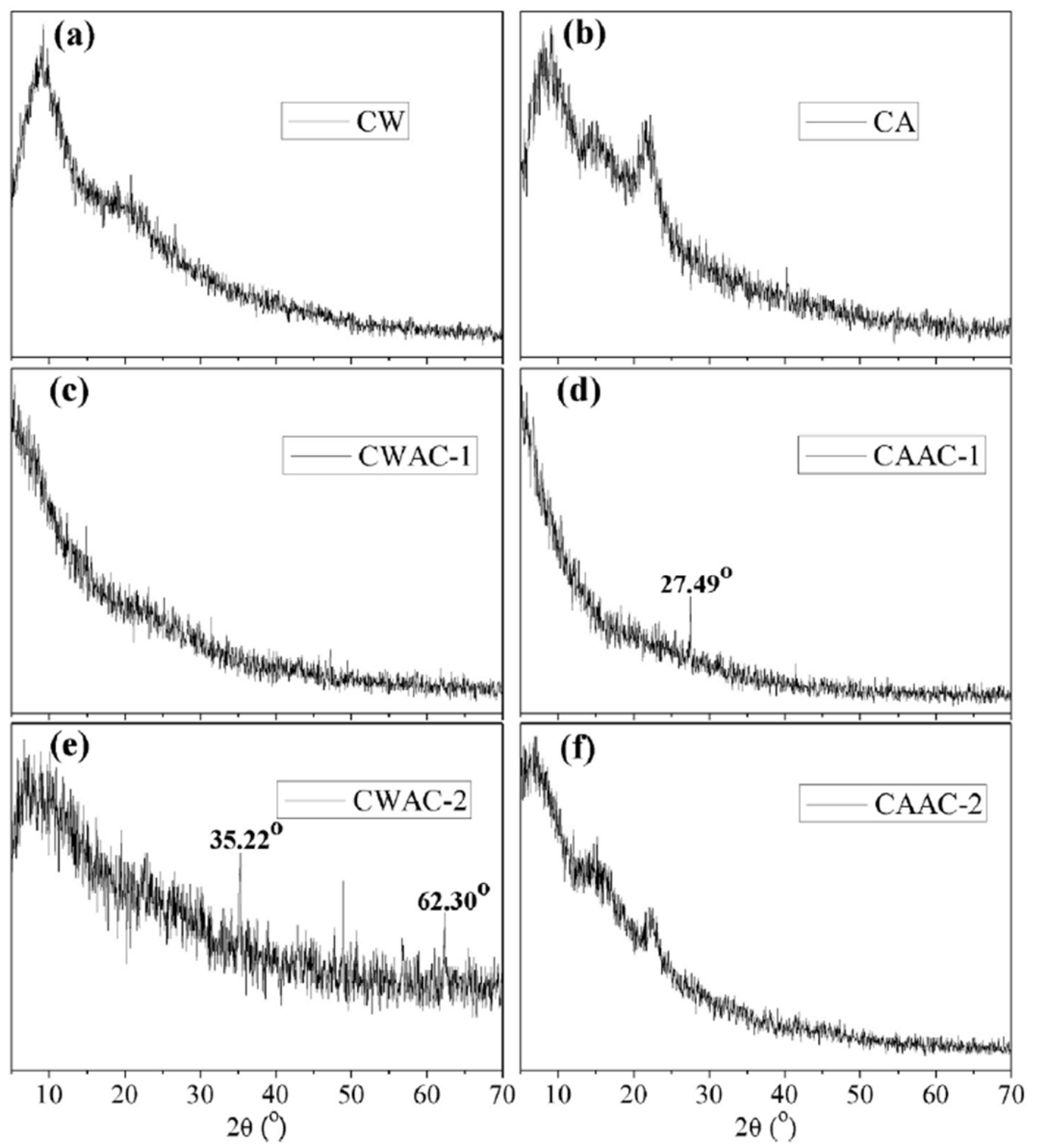

Fig. 9. XRD curves of $\mathrm{CW}, \mathrm{CA}$, and $\mathrm{CWAC}(\mathrm{a}, \mathrm{b})$ and $\mathrm{CAAC}(\mathrm{c}, \mathrm{d})$.

\section{Conclusions}

The activation temperature, $\mathrm{K}_{2} \mathrm{SiO}_{3}$ /precursor weight ratio, and pre-treatment have significant effect on the porosity and surface area; CWAC-1 and CAAC-1 possess high surface area of 1965 and $1710 \mathrm{~m}^{2} / \mathrm{g}$, respectively. The pores of CWAC are more uniform than those of $\mathrm{CAAC}$ at the activation temperature of $700{ }^{\circ} \mathrm{C}$ and with $\mathrm{K}_{2} \mathrm{SiO}_{3} /$ precursor weight ratio of 2:1. In comparison with CAAC, CWAC exhibits high content of oxygen-containing functional groups. Some new functional groups emerged after activation, such as abundance of carbonoxygen functional groups, a number of different nitrogen functional groups and silicon- 
containing functional groups. Meanwhile, all the ACs are amorphous. The present work shows that $\mathrm{K}_{2} \mathrm{SiO}_{3}$ is a promising activating agent for AC preparation.

\section{Acknowledgments}

This research was supported by the National Natural Science Foundation of China (21007034), Technology Foresight Program of Shandong Province (2012GGE 27011), Foundation for Young Excellent Scientists of Shandong Province (BS2009NY005). The authors wish to thank for the financial support from Shanghai Tongji Gao Tingyao Environmental Science \& Technology Development Foundation (STGEF).

\section{References}

[1] A. Gundogdu, C. Duran, H.B. Senturk, M. Soylak, M. Imamoglu, Y. Onal, Physicochemical characteristics of a novel activated carbon produced from tea industry waste, J. Anal. Appl. Pyrolysis 104 (2013) 249-259.

[2] Y. Juan, Q. Ke-qiang, Preparation of activated carbon by chemical activation under vacuum, Environ. Sci. Technol. 43 (2009) 3385-3390.

[3] H. Hadoun, Z. Sadaoui, N. Souami, D. Sahel, I. Toumert, Characterization of mesoporous carbon prepared from date stems by H3PO4 chemical activation, Appl. Surf. Sci. 280 (2013) $1-7$.

[4] M.A. Nahil, P.T. Williams, Pore characteristics of activated carbons from the phosphoric acid chemical activation of cotton stalks, Biomass Bioenergy 37 (2012) 142-149.

[5] J. Sreńscek-Nazzal, W. Kamińska, B. Michalkiewicz, Z.C. Koren, Production, characterization and methane storage potential of $\mathrm{KOH}$-activated carbon from sugarcane molasses, Ind. Crop. Prod. 47 (2013) 153-159.

[6] I. Ozdemir, M. Şahin, R. Orhan, M. Erdem, Preparation and characterization of activated carbon from grape stalk by zinc chloride activation, Fuel Process. Technol. 125 (2014) 200 206.

[7] W. Li, L.-B. Zhang, J.-H. Peng, N. Li, X.-Y. Zhu, Preparation of high surface area activated carbons from tobacco stems with $\mathrm{K}_{2} \mathrm{CO}_{3}$ activation using microwave radiation, Ind. Crop. Prod. 27 (2008) 341-347.

[8] K.Y. Foo, B.H. Hameed, Utilization of rice husks as a feedstock for preparation of activated carbon by microwave induced $\mathrm{KOH}$ and $\mathrm{K}_{2} \mathrm{CO}_{3}$ activation, Bioresour. Technol. 102 (2011) 9814-9817. 
[9] M.A. Lillo-Ródenas, J. Juan-Juan, D. Cazorla-Amorós, A. Linares-Solano, About reactions occurring during chemical activation with hydroxides, Carbon 42 (2004) 13711375 .

[10] R. Song, L. Chang, B. Li, Flame retardancy and thermal properties of carboxylcontaining polysiloxane derivatives in polycarbonate, J. Appl. Polym. Sci. 131 (2014).

[11] L. Huang, J. Kong, W. Wang, C. Zhang, S. Niu, B. Gao, Study on Fe(III) and Mn(II) modified activated carbons derived from Zizania latifolia to removal basic fuchsin, Desalination 286 (2012) 268-276.

[12] Q. Shi, J. Zhang, C. Zhang, C. Li, B. Zhang,W. Hu, J. Xu, R. Zhao, Preparation of activated carbon from cattail and its application for dyes removal, J. Environ. Sci. 22 (2010) 91-97.

[13] L. Huang, Y. Sun, Q. Yue, Q. Yue, L. Li, B. Gao, Adsorption of Cd (II) on lotus stalks derived activated carbon: batch and column studies, Desalin. Water Treat. 41 (2012) 122130 .

[14] H. Deng, G. Li, H. Yang, J. Tang, J. Tang, Preparation of activated carbons from cotton stalk by microwave assisted $\mathrm{KOH}$ and K2CO3 activation, Chem. Eng. J. 163 (2010) $373-$ 381 .

[15] R. Hoseinzadeh Hesas, A. Arami-Niya, W.M.A. Wan Daud, J.N. Sahu, Comparison of oil palm shell-based activated carbons produced by microwave and conventional heating methods using zinc chloride activation, J. Anal. Appl. Pyrolysis 104 (2013) 176-184.

[16] W. Chen, X. Liu, R.L. He, T. Lin, Q.F. Zeng, X.G.Wang, Activated carbon powders from wool fibers, Powder Technol. 234 (2013) 76-83.

[17] H. Liu, J. Zhang, N. Bao, C. Cheng, L. Ren, C. Zhang, Textural properties and surface chemistry of lotus stalk-derived activated carbons prepared using different phosphorus oxyacids: adsorption of trimethoprim, J. Hazard. Mater. 235-236 (2012) 367-375.

[18] D. Angin, Production and characterization of activated carbon from sour cherry stones by zinc chloride, Fuel 115 (2014) 804-811.

[19] S. Brunauer, L.S. Deming, W.E. Deming, E. Teller, On a theory of the van der Waals adsorption of gases, J. Am. Chem. Soc. 62 (1940) 1723-1732.

[20] N. Ferrera-Lorenzo, E. Fuente, I. Suárez-Ruiz, B. Ruiz, KOH activated carbon from conventional and microwave heating system of a macroalgae waste from the agar-agar industry, Fuel Process. Technol. 121 (2014) 25-31.

[21] F. Caturla, M.Molina-Sabio, F. Rodríguez-Reinoso, Preparation of activated carbon by chemical activation with ZnCl2, Carbon 29 (1991) 999-1007.

[22] J. Yang, Z. Shen, Z. Hao, Preparation of highly microporous and mesoporous carbon from the mesophase pitch and its carbon foams with KOH, Carbon 42 (2004) 1872-1875. 
[23] J. Kong, Q. Yue, L. Huang, Y. Gao, Y. Sun, B. Gao, Q. Li, Y. Wang, Preparation, characterization and evaluation of adsorptive properties of leather waste based activated carbon via physical and chemical activation, Chem. Eng. J. 221 (2013) 62-71.

[24] J. Guo, B. Gui, S.-X. Xiang, X.-T. Bao, H.-J. Zhang, A. Lua, Preparation of activated carbons by utilizing solid wastes from palm oil processing mills, J. Porous. Mater. 15 (2008) $535-540$.

[25] R. Yang, G. Liu, X. Xu, M. Li, J. Zhang, X. Hao, Surface texture, chemistry and adsorption properties of acid blue 9 of hemp (Cannabis sativa L.) bast-based activated carbon fibers prepared by phosphoric acid activation, Biomass Bioenergy 35 (2011) 437-445.

[26] Y. Sun, Q. Yue, B. Gao, Y. Wang, Y. Gao, Q. Li, Preparation of highly developed mesoporous activated carbon by $\mathrm{H} 4 \mathrm{P} 2 \mathrm{O} 7$ activation and its adsorption behavior for oxytetracycline, Powder Technol. 249 (2013) 54-62.

[27] I. Okman, S. Karagöz, T. Tay, M. Erdem, Activated carbons fromgrape seeds by chemical activation with potassium carbonate and potassium hydroxide, Appl. Surf. Sci. 293 (2014) 138-142.

[28] A.M. Puziy, O.I. Poddubnaya, A. Martínez-Alonso, F. Suárez-García, J.M.D. Tascón, Surface chemistry of phosphorus-containing carbons of lignocellulosic origin, Carbon 43 (2005) 2857-2868.

[29] S. Biniak, G. Szymański, J. Siedlewski, A. Swiatkowski, The characterization of activated carbons with oxygen and nitrogen surface groups, Carbon 35 (1799-1810) (1997).

[30] H. Liu, X.Wang, G. Zhai, J. Zhang, C. Zhang, N. Bao, C. Cheng, Preparation of activated carbon from lotus stalks with the mixture of phosphoric acid and pentaerythritol impregnation and its application for Ni (II) sorption, Chem. Eng. J. 209 (2012) 155-162.

[31] W. Liu, J. Zhang, C. Cheng, G. Tian, C. Zhang, Ultrasonic-assisted sodium hypochlorite oxidation of activated carbons for enhanced removal of Co (II) from aqueous solutions, Chem. Eng. J. 175 (2011) 24-32.

[32] E. Lorenc-Grabowska, G. Gryglewicz, M.A. Diez, Kinetics and equilibrium study of phenol adsorption on nitrogen-enriched activated carbons, Fuel 114 (2013) 235-243.

[33] N. Yoshizawa, K. Maruyama, Y. Yamada, M. Zielinska-Blajet, XRD evaluation of $\mathrm{CO}_{2}$ activation process of coal- and coconut shell-based carbons, Fuel 79 (2000) 1461-1466.

[34] L. Huang, Y. Sun, W.Wang, Q. Yue, T. Yang, Comparative study on characterization of activated carbons prepared by microwave and conventional heating methods and application in removal of oxytetracycline (OTC), Chem. Eng. J. 171 (2011) 1446-1453. 